\title{
ANNOTATION
}

\section{Broadcasting and Medicine}

Recently the B.B.C. has arranged a series of short addresses on medical matters, the object of these being to acquaint the lay public with important facts regarding preventive medicine, hygiene, diet and the serious significance of some of the symptoms and physical signs in certain diseases.

Among this series a broadcast has been given on the subject of squint. It seems that much good could be done and some harm prevented by presenting to the public in plain and simple terms the important facts about diseases which, because of their insidious onset may be neglected or receive improper attention. In ophthalmology glaucoma, squint, intracranial diseases causing visual disturbances, vascular disorders such as transient closure of the central retinal artery, the toxic amblyopias, retinal detachment and the causes of gradual loss of sight in other diseases would afford material for broadcasts.

It seems from the response to these talks that a proportion of the public desire correct information on important matters of health. If these broadcasts are to be continued and extended it will obviously be desirable to have them carefully controlled and supervised. It would be well to have the material edited by a medical board and for it to be in a form that is simple, direct and would be readily understood by the laity. For obvious ethical reasons the identity of the medical broadcaster should remain anonymous to the public, therapeutic advice should not be given and any correspondence which might follow a broadcast should not be answered by the broadcaster. The dangers of the laity undertaking self treatment without having had a medical examination and the hazards of conducting affairs of health by correspondence are obvious.

Broadcasting has come to occupy an important place in the life of the people and could be undoubtedly a strong instrument in shaping public opinion. It may well be of service in influencing public health and in educating the people to seek proper medical advice on matters of serious significance. And it would prevent much avoidable suffering and irremediable loss of structure and function from disease that has been allowed to continue untreated. To some extent such broadcasts might afford a useful weapon with which to combat the pseudo-science and the sensational and untruthful rubbish which is written about medical discoveries and treatment in the popular press. 